PREPARED FOR THE U.S. DEPARTMENT OF ENERGY, UNDER CONTRACT DE-AC02-76CH03073

PPPL-3886

PPPL-3886

UC-70

A Compact Quasi-axisymmetric Stellarator Reactor

by

L.P. Ku and the ARIES-CS Team

October 2003

N/M

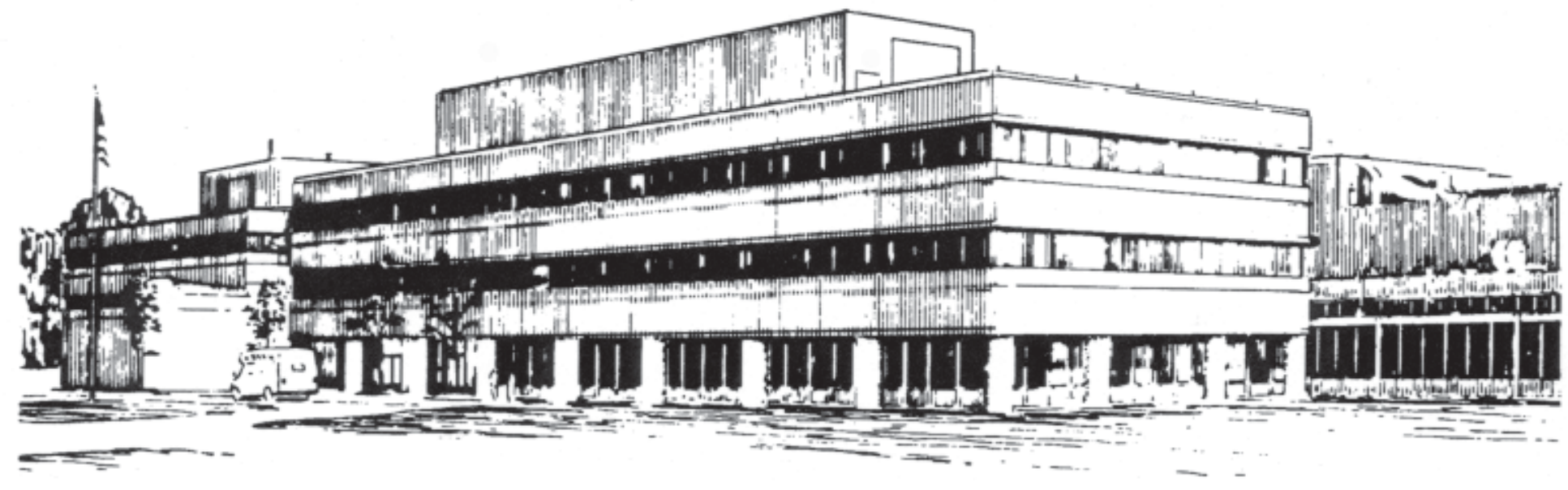

PRINCETON PLASMA PHYSICS LABORATORY PRINCETON UNIVERSITY, PRINCETON, NEW JERSEY 


\section{PPPL Reports Disclaimer}

This report was prepared as an account of work sponsored by an agency of the United States Government. Neither the United States Government nor any agency thereof, nor any of their employees, makes any warranty, express or implied, or assumes any legal liability or responsibility for the accuracy, completeness, or usefulness of any information, apparatus, product, or process disclosed, or represents that its use would not infringe privately owned rights. Reference herein to any specific commercial product, process, or service by trade name, trademark, manufacturer, or otherwise, does not necessarily constitute or imply its endorsement, recommendation, or favoring by the United States Government or any agency thereof. The views and opinions of authors expressed herein do not necessarily state or reflect those of the United States Government or any agency thereof.

\section{Availability}

This report is posted on the U.S. Department of Energy's Princeton Plasma Physics Laboratory Publications and Reports web site in Fiscal Year 2004. The home page for PPPL Reports and Publications is: http://www.pppl.gov/pub_report/

DOE and DOE Contractors can obtain copies of this report from:

U.S. Department of Energy

Office of Scientific and Technical Information

DOE Technical Information Services (DTIS)

P.O. Box 62

Oak Ridge, TN 37831

Telephone: (865) 576-8401

Fax: (865) 576-5728

Email: reports@adonis.osti.gov

This report is available to the general public from:

National Technical Information Service

U.S. Department of Commerce

5285 Port Royal Road

Springfield, VA 22161

Telephone: $1-800-553-6847$ or

(703) $605-6000$

Fax: (703) 321-8547

Internet: http://www.ntis.gov/ordering.htm 


\title{
A COMPACT QUASI-AXISYMMETRIC STELLARATOR REACTOR
}

\author{
L. P. Ku and the ARIES-CS Team \\ Princeton Plasma Physics Laboratory, P. O. Box 451, Princeton, NJ 08543-0451
}

\begin{abstract}
We report the progress made in assessing the potential of compact, quasi-axisymmetric stellarators as powerproducing reactors. Using an aspect ratio $A=4.5$ configuration derived from NCSX and optimized with respect to the quasiaxisymmetry and MHD stability in the linear regime as an example, we show that a reactor of $1 \mathrm{GW}(\mathrm{e})$ maybe realizable with a major radius $\leq 8 \mathrm{~m}$. This is significantly smaller than the designs of stellarator reactors attempted before. We further show the design of modular coils and discuss the optimization of coil aspect ratios in order to accommodate the blanket for tritium breeding and radiation shielding for coil protection. In addition, we discuss the effects of coil aspect ratio on the peak magnetic field in the coils.
\end{abstract}

\section{INTRODUCTION}

Stellarators with an underlying quasi-symmetric magnetic field structure have attracted intense interests in recent years because of the favorable particle drift trajectories in such configurations. In particular, compact, quasi-axisymmetric devices, which combine the feature of good particle orbits of a tokamak and the potential of being able to operate with MHD stable plasmas that are resistant to disruption at high pressure afforded by the three-dimensional shaping, open a new window of opportunity for confining steady-state, high $\beta$ plasmas in magnetic fusion. A low aspect ratio $(\mathrm{A}=4.5)$, proof-of-principle device, NCSX, the National Compact Stellarator Experiment, is being designed and operation is expected to commence in 2007 [1][2]. In conjunction with the development of NCSX, a reactor studies project, ARIES-CS, has been initiated to examine the competitiveness and the critical issues of compact stellarators as power producing reactors.

The development of NCSX as well as the recent reactor configurations for ARIES-CS is made possible by the advent of efficient optimization involving a large number of state variables as well as constraint functions. In arriving at a configuration, a number of optimization steps may be involved. Typically, the optimization of plasma properties, such as the amount of rotational transform or MHD stability, is accomplished by varying the shape of the last closed magnetic surface (LCMS), which is described frequently by a double Fourier series in some toroidal and poloidal angles. The coil configuration that would reproduce the desirable plasma is then "reverse engineered" by matching the normal component of the magnetic field intensity from the plasma and coils on the LCMS. Coil shapes and locations are varied in this case, typically involving several hundred variables. Due to discrete nature of the coils, using the "reverse engineering" to obtain a coil design often results in the degraded performance of the plasma. Thus, direct optimization of plasma properties simultaneously with parameters important for operational considerations (e.g., scrape-off layer thickness) and coil engineering (e.g., coil-coil spacing, bend radii, current density) may be required as a final step, again by representing coil structure as the state variable.

The optimizer we built allows multiple target and constraint functions that can be "plugged-in" as individual modules. The target modules include parameters concerning the basic properties such as the magnetic shear, magnetic well depth, and the amount of external rotational transforms. Included are also measures of MHD stability such as modes of external kinks, vertical displacement, and infinite-n ballooning, and figure of merits for transport, such as the effective ripple or diffusion coefficient evaluations, and the loss of collisionless fast ions. A discussion of optimization of the plasma properties for NCSX and our recent work for the minimization of $\alpha$ losses may be found in [3] [4].

For a power-producing reactor, there are additional important parameters needing careful considerations. Chief among these is the coil aspect ratio, the ratio of the major radius to the minimum separation between LCMS and the centerline of the coils, which perhaps is one of the most important parameters determining the size and therefore the cost of a reactor. The constraint of the maximum magnetic field in the coil body in the design of super-conducting magnets is also critical, as well as the impact of coil topology on remote maintenance and the systems optimization of the cost of electricity. In this paper, we show, by way of a sample configuration, that a $1 \mathrm{GW}(\mathrm{e})$ reactor may be realizable with a major radius $\leq 8 \mathrm{~m}$. This is significantly smaller than the ones previously attempted, e.g., those in [5]. We emphasize that the development of a compact stellarator reactor is still at an early stage that we have yet to pull all aspects of plasma physics and coil engineering together into a coherent design. However, it is important to illustrate that the potential of designing compact stellarator reactors exists that maybe competitive with other magnetic confinement concepts both on the economical and technological scales.

\section{A Plasma CONFIGURATION WITH ASPECT RATIO 4.5}

In Fig. 1 we show the last closed magnetic surface of a configuration with an aspect ratio 4.5 whose properties are similar to those of NCSX. The boundary shape is designed such that the plasma is stable, based on numerical calculations, to the vertical displacement without the need of feedback stabilization, and is also stable to the $\mathrm{N}=1$ external kink mode and ballooning modes at $\beta=4 \%$. The configuration 
has excellent quasi-axisymmetry, measured by the effective ripple [6], which is everywhere $<1 \%$. Despite this small residue non-axisymmetry, the loss of $\alpha$ may be sensitive to the details of the ripple distribution and further improvement will be needed.

The power output, $P$, is proportional to $\beta^{2} B^{4} R^{3} / A^{2}$, with the proportionality constant being the normalized, volumeaveraged fusion reactivity. Here, $\beta$ is the ratio of volume averaged plasma pressure to the magnetic pressure, $\mathrm{B}$ is the reference magnetic field at the axis, $\mathrm{R}$ is the plasma major radius, and $\mathrm{A}$ is the plasma aspect ratio defined as the ratio of the plasma major radius to the average minor radius around the torus. The ignition is attained when the power outflow is balanced by the power input from the charged fusion products, the $\alpha$ in the case of DT fusion. A systems code study [7] showed that ignition may be achieved with $\mathrm{R}=8.3 \mathrm{~m}$, $\mathrm{B}=6.5 \mathrm{~T}$ and $\beta=4.1 \%$, producing $1 \mathrm{GW}(\mathrm{e})$ power, if the ISS95 [8] scaling is used with an " $\mathrm{H}$ " factor of 3. Under this condition, the plasma has a current of $4.5 \mathrm{MA}$, all due to bootstrap. The current accounts for only $\sim 25 \%$ of the overall rotational transform. The average density and temperature of ions/electrons are $\sim 2 \cdot 10^{20} \mathrm{~m}^{-3}$ and $\sim 12 \mathrm{keV}$, respectively. The corresponding neutron wall load is $2 \mathrm{MW} / \mathrm{m}^{2}$. Alternatively, ignition may also be achieved with the same size at $\mathrm{B}=5.3 \mathrm{~T}$, but with $\beta=6.5 \%$. Thus, a machine of smaller size may be realized if we can find a configuration with a smaller aspect ratio that is also stable at a higher beta. However, in a DT reactor, because of the tritium breeding and shielding required to protect coil windings, consideration given above based solely on the plasma properties is not adequate. One has to be able to find coils that are not only capable of producing plasmas with the desirable properties, but also sufficiently away from the plasma to provide enough room for the blanket and shielding. Because the high order harmonics of the magnetic field decay rapidly, it may not be always feasible to place coils at an arbitrary distance from the plasma.

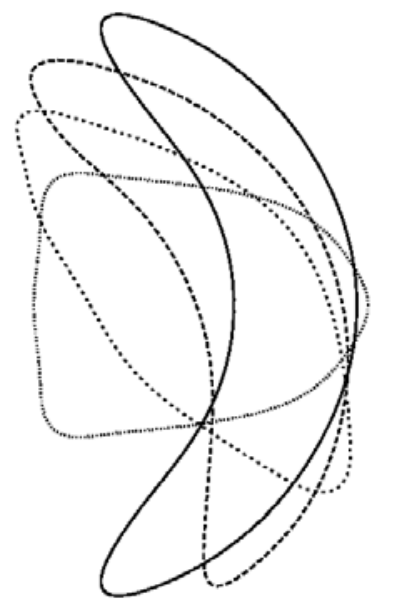

Fig. 1. The Last Closed Magnetic Surface (LCMS) shown in four equal toroidal sections in half a period for an $\mathrm{A}=4.5$ quasi-axisymmetric configuration whose properties are similar to those of NCSX. The shaping of the plasma results in a vacuum rotational transform from 0.42 to 0.48 , which accounts for more than $70 \%$ of the total.

\section{COILS AND ASPECT RATIO OPTIMIZATION}

As outline in section I, coils that produce the desired plasma shape (hence, its properties) may be designed by requiring that the normal component of the magnetic field on the LCMS due to the coils cancel that due to the plasma current. Because of the discrete nature of the coils, the normal field on LCMS may not be canceled exactly, but the errors may be minimized. We require in this study that the average residual error be $<0.5 \%$ and the maximum error be $<2 \%$. Additional constraints, such as the minimum coil-to-coil separation and minimum coil-to-plasma separation may be imposed. We have examined coil designs with the minimum coil to plasma separation from 1.2 to $1.5 \mathrm{~m}$, subject to the constraint that the minimum coil-coil separation be greater than $0.85 \mathrm{~m}$. We considered only the "modular" coils in this study in which the coils are wound poloidally around the torus but they may assume arbitrary shapes. Typical planer $1 / R$ coils, as well as poloidal field coils, may be superimposed to allow manipulation of the ratio of poloidal to toroidal fields. An example of a modular coil set, two pairs of three distinctive types per field period, is shown in fig. 2. This coil set has the basic topology similar to that of the NCSX.

We note that even with the prescribed small tolerance in the normal field errors, the plasma the coil produces may not necessarily have all the targeted properties. Direct optimization of the plasma properties discussed in section I may still be required, but this is a much more expensive process and should be done only after a limited set of coil options is finally chosen.

For a DT reactor, the tritium breeding and coil protection from radiation damage typically require a blanket and shield thickness in excess of $1.2 \mathrm{~m}$. Fig. 3 shows the separation between the coil winding surface and the LCMS for a coil set which has a coil aspect ratio of 6.8. The separation varies
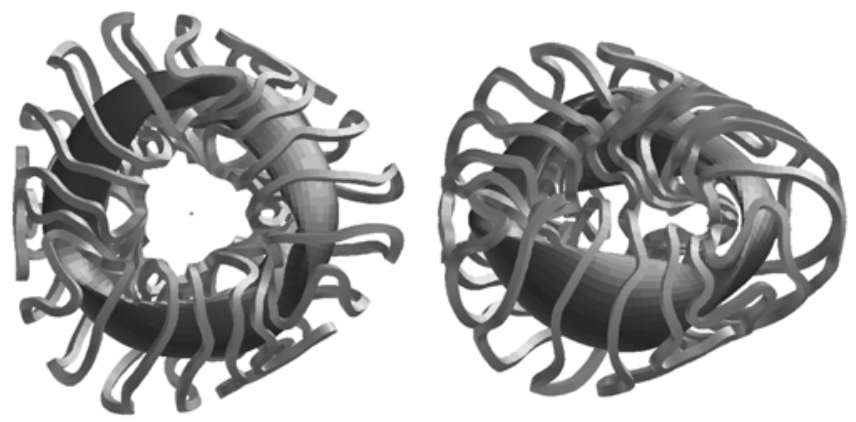

Fig. 2. Top and perspective views of a modular coil design with coil aspect ratio 6. The LCMS of the plasma is also shown. In this design, there are three distinctive types of coils for a total of 18 coils in three field periods. Conventional $1 / \mathrm{R}$ planer (TF) coils as well as poloidal field coils are also used, but are not shown. The major radius of the plasma is $8.3 \mathrm{~m}$. The minimum distance from the plasma to the coil centerline is $1.4 \mathrm{~m}$, and the minimum coil-to-coil separation is $0.83 \mathrm{~m}$. The minimum radius of curvature of the coils is $0.62 \mathrm{~m}$. The maximum coil current for $\mathrm{B}(0)=6.5 \mathrm{~T}$ is $16.5 \mathrm{MA}$. 


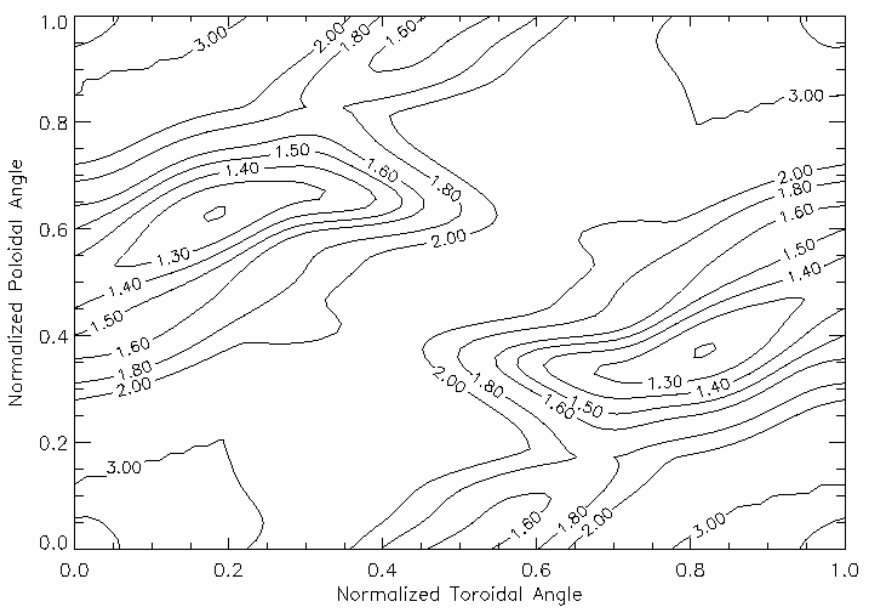

Fig. 3. Contours of distance (meter) from LCMS of the plasma shown in fig. 1 to the winding surface of a modular coil set whose topology is similar to that shown in fig. 2 but it has a coil aspect ratio 6.8 . The normalized poloidal angle is $\theta / 2 \pi$ and the normalized toroidal angle is $\mathrm{Np} \cdot \phi / 2 \pi$, where $\mathrm{Np}$ is the number of field period.

poloidally and toroidally. The minimum separation is about $1.2 \mathrm{~m}$, which is not adequate for the blanket and shield. The region where the separation is less than $1.4 \mathrm{~m}$, however, is no more than $10 \%$. High quality shield, e.g., tungsten carbide, may be used in this small region that would substantially reduce the local radial build $(<1 \mathrm{~m})$ without affecting the overall tritium breeding. Still, the tightness of space implies that the coil cross section has to be limited, which may result in high local current density and peak magnetic field, making the design of super-conducting coils difficult. There is clearly an incentive to reduce the coil aspect ratio to the extent possible. Decreasing the coil aspect ratio makes the coils more complex because of the rapid decay of high order harmonic contents of the magnetic field, which in turn may increase the peak field in the coil body. Fig. 4 shows the peak magnetic field in the coil as the coil aspect ratio is changed. It is seen that there is a minimum coil aspect ratio $\sim 6$ below which the increased coil current and coil complexity will give rise to higher fields in the coil body, and above which the high coil current density due to the space limitation will also give rise to higher fields. For a reactor of $\mathrm{R} \sim 8.3 \mathrm{~m}$ at $6.5 \mathrm{~T}$, the coils with a coil aspect ratio 6 shown in fig. 2 has a minimum coil to plasma separation $\sim 1.4 \mathrm{~m}$, minimum coil-coil separation $\sim 0.83$ $\mathrm{m}$, maximum coil current 16.5 MA, and peak magnetic field $\sim 11 \mathrm{~T}$.

A smaller coil aspect ratio allows a smaller sized reactor if the required radiation shielding is minimized. Using a minimum spacing of $1.1 \mathrm{~m}$ to accommodate radiation shielding, vacuum vessel, insulation, coil case, and the plasma scrape-off, we show in fig. 5 the peak magnetic field in the coil as a function of the plasma major radius for the same reactor power. In arriving at fig. 5, we fixed the plasma beta at $4.1 \%$, but adjusted magnetic field on axis to compensate for the change in major radius $\left(\mathrm{B} \propto 1 / \mathrm{R}^{3 / 4}\right)$. A machine with a major radius as small as $7.3 \mathrm{~m}$ may be possible when the peaked field in the coil is limited to $14 \mathrm{~T}$. Of course, one has to take into account the effects on the particle confinement as the reactor size and magnetic field change, and the effects due to the change in neutron wall loading as well. Ultimately, a systems level study will be needed to come to an optimized design.

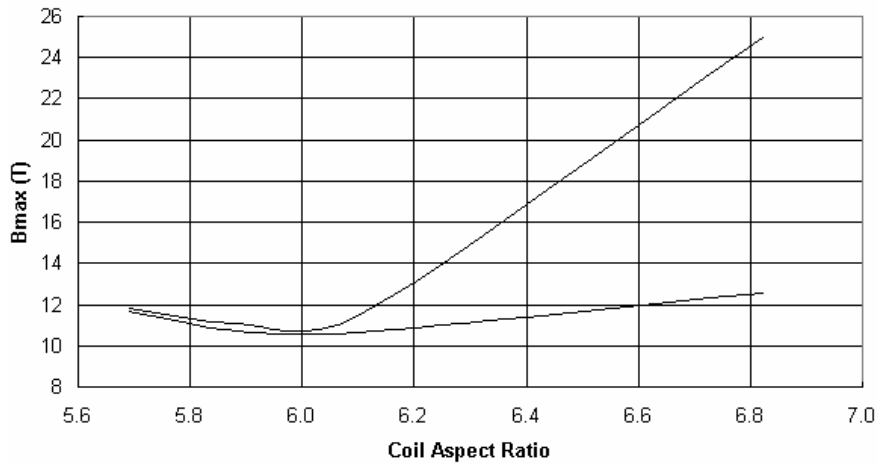

Fig. 4. The maximum magnetic field intensity in coils versus coil aspect ratio for modular coils with a topology similar to that shown in fig. 2 which are designed to produce the plasma shown in fig. 1, with a major radius of $8.3 \mathrm{~m}$ and the field on axis $6.5 \mathrm{~T}$. We have assumed that the overall minimum thickness required for blanket/shield, plasma scrape-off, thermal insulation, coil case, etc., to be $1.1 \mathrm{~m}$, and the remaining minimum space available is used for the radial dimension of the coil conductor. The top curve is for conductors with square cross sections; the bottom curve is for conductors with fixed width of $0.4 \mathrm{~m}$.

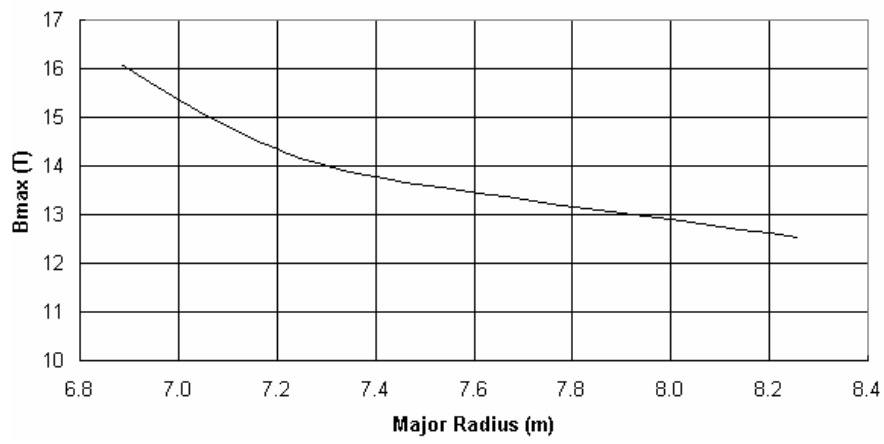

Fig. 5. The maximum magnetic field intensity in coils versus the minimum major radius of the plasma for a configuration shown in fig. 1 that yields the same fusion power as the one with $\mathrm{R}=8.3 \mathrm{~m}, \mathrm{~B}(0)=6.5 \mathrm{~T}$. We have assumed the same loss rate for $\alpha$ particles and also the same minimum coil-plasma spacing of $1.2 \mathrm{~m}$. The coil cross section has a width of $90 \%$ of the minimum coil-coil spacing and a radial thickness $0.2 \mathrm{~m}$.

\section{SUMMARY AND CONCLUSIONS}

We have started to examine the reactor potential of quasiaxisymmetric stellarators with an integrated approach that includes systems evaluation, engineering considerations and plasma and coil optimizations. In this paper, we summarize the progress made in developing a QA configuration with the optimized coil aspect ratio. In a separate paper [4], we summarized the progress made in developing configurations with the reduced $\alpha$ loss. To allow remotely maintaining coils and machine components in a reactor environment, there is a 
desire to simplify to the extent possible the plasma and coil design. To this end, finding a plasma configuration that integrates optimization of $\alpha$ loss and MHD stability, minimization of systems cost, and maximization of the good coil and reactor performance, remains to be an extremely challenging task.

\section{ACKNOWLEDGMENT}

The author would like to acknowledge the contribution from the ARIES-CS team whose member consists of J. Lyon of ORNL, L. Bromberg of MIT, L. Waganer of Boeing High Energy Systems, A. Turnbull of GA, P. Garabedian of NYU, L. El-Guebaly of University of Wisconsin, T. K. Mau, F. Najmabadi, R. Raffray, X. Wang of UCSD, and M. Zarnstorff, H. Neilson and J. Schmidt of PPPL. This work was supported by the United States Department of Energy Contract No. DE-AC02-76-CHO-3073.

\section{REFERENCES}

[1] G. H. Neilson, M. Zarnstorff, L. P. Ku, et al., "Physcics Considerations in the Design of NCSX," IAEA-CN-94/IC-1 $19^{\text {th }}$ International Atomic Energy Agency Fusion Energy Conference. Lyon, France, October 1419, 2002.

[2] B. E. Nelson, A. Brooks, R. D. Benson, et al., "Engineering Aspects of Compact Stellarators," IAEA-CN-94/FT/2-4 $19^{\text {th }}$ International Atomic Energy Agency Fusion Energy Conference. Lyon, France, October 1419, 2002.

[3] A. Reiman, L. Ku, D. Monticello, et al., "Recent advances in the design of quasiaxisymmetric stellarator plasma configurations," Physics of Plasma, vol. 8 No. 5, pp.2083-2094, May 2001.

[4] L. P. Ku, M. Zarnstorff, R. B. White, et al., "Development of Compact Quasi-Axisymmetric Stellarator Configurations," $14^{\text {th }}$ International Stellarator Workshop, Greifswald, Germany, September 22-26, 2003

[5] "Stellarator Power Plant Study," Final Report, UCSD-ENG-004, 1997.

[6] V. V. Nemov, S. V. Kasilov, W. Kernbichler and M. F. Heyn., "Evaluation of $1 / v$ neoclassical transport in stellarators," Physics of Plasma, vol. 6 No. 12, pp.4622-4632, December 1999.

[7] J. Lyon, Oak Ridge National Laboratory, Oak Ridge, TN, personal communication, 2003.

[8] U. Stroth et al, "Energy confinement scaling from the international stellarator databse," Nucl. Fusion, vol. 36 No. 8, pp 1063-1077, 1996. 


\section{External Distribution}

Plasma Research Laboratory, Australian National University, Australia

Professor I.R. Jones, Flinders University, Australia

Professor João Canalle, Instituto de Fisica DEQ/IF - UERJ, Brazil

Mr. Gerson O. Ludwig, Instituto Nacional de Pesquisas, Brazil

Dr. P.H. Sakanaka, Instituto Fisica, Brazil

The Librarian, Culham Laboratory, England

Mrs. S.A. Hutchinson, JET Library, England

Professor M.N. Bussac, Ecole Polytechnique, France

Librarian, Max-Planck-Institut für Plasmaphysik, Germany

Jolan Moldvai, Reports Library, Hungarian Academy of Sciences, Central Research Institute for Physics, Hungary

Dr. P. Kaw, Institute for Plasma Research, India

Ms. P.J. Pathak, Librarian, Institute for Plasma Research, India

Ms. Clelia De Palo, Associazione EURATOM-ENEA, Italy

Dr. G. Grosso, Instituto di Fisica del Plasma, Italy

Librarian, Naka Fusion Research Establishment, JAERI, Japan

Library, Laboratory for Complex Energy Processes, Institute for Advanced Study, Kyoto University, Japan

Research Information Center, National Institute for Fusion Science, Japan

Dr. O. Mitarai, Kyushu Tokai University, Japan

Dr. Jiangang Li, Institute of Plasma Physics, Chinese Academy of Sciences, People's Republic of China

Professor Yuping Huo, School of Physical Science and Technology, People's Republic of China

Library, Academia Sinica, Institute of Plasma Physics, People's Republic of China

Librarian, Institute of Physics, Chinese Academy of Sciences, People's Republic of China

Dr. S. Mirnov, TRINITI, Troitsk, Russian Federation, Russia

Dr. V.S. Strelkov, Kurchatov Institute, Russian Federation, Russia

Professor Peter Lukac, Katedra Fyziky Plazmy MFF UK, Mlynska dolina F-2, Komenskeho Univerzita, SK-842 15 Bratislava, Slovakia

Dr. G.S. Lee, Korea Basic Science Institute, South Korea

Institute for Plasma Research, University of Maryland, USA

Librarian, Fusion Energy Division, Oak Ridge National Laboratory, USA

Librarian, Institute of Fusion Studies, University of Texas, USA

Librarian, Magnetic Fusion Program, Lawrence Livermore National Laboratory, USA

Library, General Atomics, USA

Plasma Physics Group, Fusion Energy Research Program, University of California at San Diego, USA

Plasma Physics Library, Columbia University, USA

Alkesh Punjabi, Center for Fusion Research and Training, Hampton University, USA

Dr. W.M. Stacey, Fusion Research Center, Georgia Institute of Technology, USA

Dr. John Willis, U.S. Department of Energy, Office of Fusion Energy Sciences, USA

Mr. Paul H. Wright, Indianapolis, Indiana, USA 
The Princeton Plasma Physics Laboratory is operated by Princeton University under contract with the U.S. Department of Energy.

\author{
Information Services \\ Princeton Plasma Physics Laboratory \\ P.O. Box 451 \\ Princeton, NJ 08543
}

Phone: 609-243-2750

Fax: 609-243-2751

e-mail: pppl_info@pppl.gov

Internet Address: http://www.pppl.gov 